\title{
Transformações da sociedade contemporânea
}

\author{
Maria Izabel Sanches Costa \\ Aurea Maria Zöllner lanni
}

\section{SciELO Books / SciELO Livros / SciELO Libros}

COSTA, M.I.S., and IANNI, A.M.Z. Transformações da sociedade contemporânea. In: Individualização, cidadania e inclusão na sociedade contemporânea: uma análise teórica [online]. São Bernardo do Campo, SP: Editora UFABC, 2018, pp. 5-41. ISBN: 978-85-68576-95-3. https://doi.org/10.7476/9788568576953.0002.

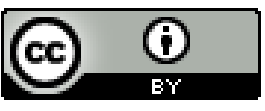

All the contents of this work, except where otherwise noted, is licensed under a Creative Commons Attribution 4.0 International license.

Todo o conteúdo deste trabalho, exceto quando houver ressalva, é publicado sob a licença Creative Commons Atribição 4.0.

Todo el contenido de esta obra, excepto donde se indique lo contrario, está bajo licencia de la licencia $\underline{\text { Creative }}$ Commons Reconocimento 4.0. 


\section{TRANSFORMACÕES DA SOCIEDADE CONTEMPORANEA}

Este capítulo dedica-se a apresentar uma análise do Lprocesso de individualização e as decorrentes transformações sociopolíticas contemporâneas. Tal estudo subsidiará as análises das categorias de cidadania e inclusão social, já que se parte do pressuposto de que essas devem ser compreendidas dentro de seu contexto sócio-histórico.

Vários são os nomes atribuídos ao atual momento histórico: pós-modernidade (BAUMAN, 2001; LIPOVETSKY, 2005a; HARVEY, 1994); modernidade líquida (BAUMAN, 2001, 1999a); modernidade reflexiva (GIDDENS; BECK; LASH, 1997); sociedade de risco e segunda modernidade (BECK, 2011); hipermodernidade (LIPOVETSKY, 2004), dentre outros. Assim como Ianni (2013, p. 43-44), utilizaremos, aqui, o termo primeira modernidade para referirmos a

[...] modernidade tradicional, aquele momento histórico em que a sociedade industrial moderna se configura, ainda, com as características da plena industrialização, da crença na assertividade da ciência e da tecnologia como expressão de razão 
e do progresso, da constituição e hegemonia dos estados-nação e o modelo de família nuclear.

Por sociedade contemporânea compreendemos "[...] um desdobramento, em autorreferência, da tradição moderna industrial; a transformação da modernidade por dentro de si mesma [...] que, no entanto, não deixa de promover mudanças estruturais na centralidade das sociedades ocidentais" (IANNI, 2013, p. 43-44).

Para Bauman (1999a), duas são as características que fazem do atual momento uma modernidade distinta da precedente ou do momento primeiro da modernidade: 1) o declínio da antiga ilusão moderna; e 2) o individualismo. A primeira refere-se à antiga crença de que há um ideal de sociedade e de Estado a ser alcançado. Para o autor, a metáfora da humanidade moderna - da ilusão moderna - era a do jardineiro. 0 jardineiro, nesse contexto, acredita na ordem do mundo e sabe exatamente qual o tipo de planta que deve crescer ou não, garantindo, assim, a construção de seu arranjo ideal. Para tal, ele precisa destruir as ervas daninhas indesejadas, que poderão alterar esse arranjo. É do jardineiro que emergem as grandes utopias norteadoras da sociedade moderna. Existiria, para ele, um projeto social, um norte para onde a sociedade deveria caminhar. Essa ideia moderna era embasada na fé do progresso da sociedade, segundo a qual a grande utopia e, consequentemente, os grandes projetos coletivos perdem espaço para o imediatismo e para os projetos individuais.

A segunda característica do momento atual, intrinsecamente ligada à primeira, é o deslocamento da ênfase do projeto coletivo para o individual. Esse individualismo realoca o discurso político, antes focado nos coletivos 
tradicionais modernos, como identidades nacionais ou de classe, por exemplo, para o lugar dos direitos humanos. Isso significa que o atual enfoque passa a ser o discurso do direito de os indivíduos serem diferentes e de escolherem seus próprios modelos de felicidade e estilos de vida. Assim, para o autor, sob o ponto de vista da dinâmica social, o elemento integrador da coesão social moderna desmoronou-se, pois não há mais um projeto coletivo mobilizador.

Com uma linha de pensamento convergente com a de Bauman (1999a), Lyotard (2002) afirma que esse novo momento é a época em que as grandes narrativas perdem a credibilidade e a admiração dos indivíduos e, portanto, a capacidade de domínio das consciências. Tais são os enunciados que marcam a emergência de novos paradigmas na sociedade contemporânea: a incapacidade do Estado de provocar o engajamento das massas a partir de um sentimento nacionalista; as incertezas em virtude da contemplação dos cenários pós-guerra; a crise na crença dos discursos de pretensão a uma aplicabilidade universal. Com discurso que se aproxima ao de Lyotard (2002), Harvey (1994, p. 19) afirma que "[...] a fragmentação, a indeterminação e a intensa desconfiança de todos os discursos universais ou (para usar um termo favorito) totalizantes são o marco do pensamento pós-moderno".

Compreende-se, assim, de acordo com os autores citados anteriormente, que o momento histórico do pós-guerra redimensionou a credibilidade de que desfrutavam as metanarrativas, bem como das instituições que lhes davam suporte. Iniciou-se uma fase de desconfianças dos discursos universais e cresceram as incertezas perante o futuro. A partir dessa crise, intensificaram-se o individualismo e a crise dos absolutos, a relativização do agir e 
do pensamento ético, bem como acentuaram-se a dimensão do viver no presente e a escassez do engajamento em massa. Em consequência dessas transformações, os interesses e as trajetórias individuais suplantaram os coletivos (BECK, 2011; BAUMAN, 2001; LIPOVETSKY, 2005a).

\section{O PROCESSO DE INDIVIDUALIZAÇÃO}

A noção de indivíduo é profundamente histórica e nem sempre existiu com os significados que lhe atribuímos atualmente. Acredita-se que indivíduo é um termo eminentemente moderno, que remonta ao Iluminismo e à ideia da libertação pela razão (MATEUS, 2011). Até o fim da Idade Média, o homem encontrava-se submisso à coletividade em que estava inserido, às relações de tradição, aos costumes e a um papel previamente determinado pelo seu nascimento. A identidade do homem tradicional era claramente definida e fixa. A vida era organizada por instituições rígidas e coletivas.

No advento da modernidade, emergiu a noção de indivíduo e sua prevalência sobre a noção do coletivo, o que quer dizer que a ênfase iluminista sobre o homem autônomo e racional trouxe mudanças fundamentais ao entendimento do indivíduo e de sua relação com a tradição, a obediência e a sociedade.

Inerente à emancipação da razão, esteve a reivindicação da liberdade como espaço reservado à autodeterminação de cada indivíduo em face do Estado. De fato, a liberdade dos modernos é a liberdade de não interferência sobre a intimidade do indivíduo e a favor da satisfação da independência privada. Essa liberdade moderna acirrou a 
primazia do privado sobre o público e do individual sobre o coletivo. Ela é alicerçada na emancipação do indivíduo sobre o social.

Bauman (2001, p. 39) ressalta que "[...] a apresentação dos membros como indivíduos é a marca registrada da sociedade moderna". É somente com a modernidade que a ideia de liberdade individual ganha ênfase.

É importante frisar que há uma diferença entre a individualização da primeira modernidade e a da sociedade contemporânea. Se a individualização dos séculos XVIII e XIX tinha como ideal a liberdade e a igualdade, a individualização que emergiu na segunda metade do século XX tem como ideal a distinção e a diferença. Esta evidencia que, na primeira modernidade, a igualdade ainda era um valor tão ou mais importante que a liberdade, ou seja, a individualização, apesar de importante, era algo secundário. Como Bauman (1999a) demonstra, a primeira modernidade foi marcada por um esforço de eliminação da ambivalência e de qualquer coisa que pudesse causar alguma desordem e atrapalhar a busca por uma sociedade planejada e ordenada, o que tornava qualquer diferenciação um tanto perigosa.

Os Estados nacionais modernos possuíam certa exigência de homogeneidade interna das identidades, constrangendo e até mesmo impedindo a proliferação da individualidade como ideário de distinção. No entanto, os indivíduos eram entendidos como livres e iguais, podendo exercer direitos e deveres perante a sociedade e o Estado, bem como sendo responsabilizados por suas ações. Além disso, sua identidade era previamente determinada por sua nacionalidade, gênero, classe social, profissão e família. 
Beck (2011) diz que, com o advento da modernidade, introduziu-se um modelo de individualização tripla: 1. desprendimento das formações e dos vínculos sociais estabelecidos historicamente; 2. perda das seguranças tradicionais; e, por último, 3. aparecimento de uma nova forma de enquadramento social, como resultado das anteriores. Isso quer dizer que, no processo de desenvolvimento político-econômico, no contexto da passagem da primeira modernidade para a chamada segunda modernidade (ou sociedade contemporânea), os indivíduos são libertados das formas sociais típicas da sociedade industrial, tais como os estratos e as classes sociais, a família, o gênero etc.

Com efeito, começa-se a desenhar uma concepção de indivíduo alicerçada na formulação de liberdade que visa ao alcance das condições necessárias para a construção de um projeto de vida próprio, individualizado, com opções de escolhas, possibilidades e decisões que só podem ser tomadas por si mesmo. De acordo com o autor, esse processo significa que o indivíduo, como agente de ação, pode definir suas formas de vida individuais, e coletivas e, portanto, tornar-se expressão das suas próprias escolhas, despregando-se, mais e mais, das amarras das formas sociais coletivas tradicionais modernas.

Com uma linha de raciocínio similar à de Beck (1997), Giddens (1997) entende que a biografia do indivíduo contemporâneo é um constructum formado de um continuum, caminho percorrido e a ser percorrido.

Dessa forma, pode-se concluir que a biografia individual é apresentada, para ambos os autores, como um projeto reflexivo, um conjunto aberto de possibilidades que requerem decisões constantes do indivíduo. 
De acordo com Beck (1997), o processo de individualização deve ser entendido no âmbito dos processos de formação e constituição social, no qual o indivíduo passa a ser a referência central das ações do mundo social. Isso faz com que a percepção sobre os mecanismos e os processos sociais em geral - no contexto de individualização - sejam vistos como problemas individuais e, portanto, como se não mais estabelecidos no domínio do social. Dessa forma, assiste-se a uma decomposição das fontes de significados coletivos, que se tornam objeto de desencantamento e até mesmo de esgotamento. Tal processo conduz as instituições sociais a redefinirem as suas funções de suporte, que agora se deslocam dos grandes coletivos para os indivíduos. Isso contribui para a perda da dimensão de coletivo (BECK, 2010).

Beck (1997) considera que, quando a modernidade atinge certo nível do seu desenvolvimento, diminuem os constrangimentos das regulações estruturais sobre os indivíduos, visto que as próprias forças do processo de mudança tornam os indivíduos mais livres em relação às estruturas modernas.

Estruturada no contexto da individualização, Beck (1997) refere-se à uma mudança estrutural da vida privada, que força os indivíduos a construírem reflexivamente sua própria biografia, isto é, a tomarem as suas próprias decisões, livres de pressões estruturais.

A individualização é uma compulsão, mas uma compulsão pela fabricação, o autoprojeto e a auto-representação, não apenas pela autobiografia, mas também de seus compromissos e articulações à medida que as fases da vida mudam [...] (BECK, 1997, p. 26). 
Nas análises de Beck (1997; 2000) e Giddens (1997), a reflexividade é um conceito central e diz respeito à capacidade de os indivíduos compreenderem os acontecimentos que se passam à sua volta, de tal modo que possam relacioná-los às suas atividades naquele momento, bem como reordenar suas atividades pelo uso dessas informações. Ações reflexivas podem estar no exame e nas transformações de práticas sociais, por força de informações novas. De acordo com Giddens (1991), a sociedade moderna tornou-se crescentemente reflexiva, período marcado pela suscetível revisão de todas as atividades sociais sob a luz de novas informações e conhecimentos, o que pode ser caracterizado como um monitoramento das atividades humanas.

Com base nas teorias dos autores mencionados, pode-se concluir que todos os aspectos da vida - das práticas sociais às instituições, do associativismo à construção do eu - passam a ser construídos reflexivamente.

A modernidade reflexiva - termo utilizado pelos autores para referir a dinâmica intrínseca da sociedade moderna - vai ocupar-se, sempre e mais, em dominar e controlar os problemas autocriados, ou seja, a reflexividade significa ocupar-se com problemas e consequências do próprio processo de transformação da sociedade. Em consequência disso, as construções reflexivas implicam um processo de questionamento, de dúvidas e de escolhas. Como não há mais estruturas fixas e permanentes - sólidas, como as denominaria Bauman (2001) -, tudo está em constante construção e desconstrução. A movimentação e a agitação fazem-se sentir em todas as esferas da vida, e o indivíduo é chamado constantemente a opinar, participar, escolher e decidir sobre os mais variados assuntos.

Enquanto Beck (1997) e Giddens (1991), ao analisarem a modernização reflexiva, relacionam a excessiva 
preocupação do indivíduo consigo mesmo, com seu autodesenvolvimento e ao o fato de que as velhas ordens comunais foram rompidas, Lash (1983) associa a sociedade atual a uma característica narcísica, assim denominada por ele, sem a preocupação com o passado e o futuro. Para esses autores, os processos de modernização e individualização encontram-se imbricados, conduzindo a uma ruptura do sentido histórico nas sociedades modernas. Perde-se o sentimento de pertencimento a uma comunidade ou de continuidade geracional, por exemplo. Também se perdem os vínculos com as instituições tradicionais e os valores modernos. Para estes, perdeu-se o sentido da comunidade histórica e o sentimento de pertencer a uma geração enraizada no passado, porque o sentido histórico foi perdido com as metanarrativas, os valores tradicionais e as instituições tradicionais modernas. Os indivíduos já não mais se vinculam a instituições, mas, ao contrário, nelas e em seus valores eles não mais acreditam. Essa é uma das sequelas do declínio dos sujeitos coletivos e de suas instituições, como o Estado-Nação, a dimensão comunitária e os sindicatos, que garantiam a proteção dos indivíduos e de seus direitos. Isso não significa que não haja mais a existência de categorias como família, classe, gênero, religião, comunidades e sindicatos, mas, sim, que elas foram transformadas e, muitas vezes, relegadas a segundo plano. Não serão mais elas a guiar as biografias individuais.

Nesse sentido, Beck $(2011)^{1}$ afirma que as mudanças sociais no interior da sociedade contemporânea

\footnotetext{
1 Para Beck (2011), na Alemanha do pós-guerra, desenvolveu-se uma dinâmica socioestrutural que não pode ser explicada por meio da teoria de classe de Marx e Engels (classe definida pelo seu lugar em determinado sistema histórico de produção social e sua relação com os meios de produção). Dessa forma, o autor questiona a análise social a partir da leitura dos grandes grupos tradicionais, como classe e estamentos.
} 
(sociedade de risco - termo utilizado pelo autor) desprendem o indivíduo das formas sociais tradicionais da sociedade industrial (primeira modernidade), e, consequentemente, das categorias tradicionais (classe e estamento, por exemplo) que formavam as bases do modo de pensar a sociedade. As transformações entre indivíduos e sociedade foram tão profundas, segundo ele, que as distinções de classes sociais não determinam mais, exclusivamente, a formação das identidades. Tais mudanças não significam que desapareçam as desigualdades fundamentadas nas clivagens da primeira modernidade. 0 que ocorre é uma ressignificação com base no processo de individualização, ou seja, os problemas sociais passam a ser compreendidos também segundo a individualidade de cada um e não unicamente na sua conformação coletiva.

De acordo com Beck (1997, p. 18-19), isso conduz à imposição de todo esforço e culpabilidade sobre o próprio indivíduo:

As oportunidades, ameaças, ambivalências da biografia que, anteriormente, era possível superar em grupo familiar, na comunidade da aldeia ou se recorrendo a uma classe ou grupo social, devem ser cada vez mais percebidas, interpretadas e resolvidas pelos próprios indivíduos. Certamente ainda podem ser encontradas nas famílias, mas as famílias nucleares estão se tornando uma instituição cada vez mais rara. Há desigualdades crescentes, mas as desigualdades e a consciência de classe perderam sua posição central na sociedade.

Para o autor, a individualização não implica substituir as antigas certezas por uma situação de vazio. Ao contrário, o processo de individualização produz uma 
compulsão pela procura de novas certezas. Trata-se do surgimento de uma nova forma de conduzir a vida, já não mais presa às tradições.

Posto isso, é importante ressaltar que a individualização caminha concomitante às tendências de novas formas de institucionalização e padronização de condições de vida. Os indivíduos livres tornam-se dependentes do mercado de trabalho e, consequentemente, dependentes de qualificação e formação para conseguirem inserir-se nesse mercado, bem como dependentes da oferta e dos meios para o consumo, das regras sociojurídicas que lhes concedem direitos, da ciência, da medicina, da psicologia etc. Em suma, o processo de libertação da institucionalidade tradicional moderna aponta para outras e novas contradições, pois liberta e também produz novas dependências, que são, por sua vez, institucionalizadas e padronizadas.

Tal como Beck (1997), que analisa as transformações da sociedade contemporânea, Lipovetsky (2004) acredita que, a partir do último quarto do século $\mathrm{XX}$, a modernidade ingressou em uma fase de radicalização da modernidade, denominada por ele como hipermodernidade. $\mathrm{O}$ atual momento, hipermoderno, instantâneo e fluido, tem como característica a cultura do narcisismo, representado por uma monumental explosão do neoindividualismo.

[...] o individualismo sofre uma atualização que aqui chamamos de narcisista, de acordo com a definição dos sociólogos norte-americanos: narcisismo, consequência e manifestação miniaturizada do processo de personalização, símbolo da passagem do individualismo limitado ao individualismo total, símbolo da segunda revolução individualista (LIPOVETSKY, 2005a, p. 21). 
Para o autor, os atuais ordenamentos e instituições sociais servirão, tão somente, como objetos de escolha para os indivíduos construírem suas próprias identidades. De fato, as instituições e os organismos reguladores que, na primeira modernidade, estruturavam a escolha dos indivíduos por meio dos serviços oferecidos, agora, nesse período que o autor chama de neoindividualismo, esses serviços são utilizados de acordo com os interesses individuais e não mais em sua dimensão social ou coletiva. No livro A era do vazio, Lipovetsky (2005a) apresenta a desagregação da sociedade moderna e dos costumes, o enfoque do indivíduo contemporâneo no consumo de massa e a emergência de um modelo de individualização em ruptura com os paradigmas tradicionais dos séculos XVII e XVIII. Esse momento histórico marca um período de ruptura com todas as instituições que se opunham à liberdade e à autonomia dos indivíduos. É o momento em que freios se rompem, permitindo a emergência e a manifestação dos desejos subjetivos e sua realização individual.

A cultura pós-moderna é um vetor do aumento do individualismo; diversificando as possibilidades de escolha, liquidificando os pontos de referências, minando o sentido único e os valores superiores da modernidade, ela administra uma cultura personalizada sob medida, que permite ao átomo social emancipar-se do balizamento disciplinar revolucionário. (LIPOVETSKY, 2005a, p. 21).

Assim como Bauman (2001), Lipovetsky (2004), afirma que esse novo paradigma individualista é consentâneo a vários fatores, tais como as inovações dos meios de comunicação e do transporte, e do desenvolvimento 
das transações comerciais, inerentes ao estado atual do capitalismo, que se assume como consumista. É assim que, ancorada no individualismo, formou-se uma sociedade hedonista que envolve, quase indistintamente, todos os segmentos e classes sociais. Lipovetsky (2004) refere-se ao atual momento como a "[...] sedutora leveza do ser" e Bauman (2001) como o "[...] tempo instantâneo", no sentido de ausência e volatilidade de interesses. Se o início da modernidade foi o tempo dos engajamentos mútuos, a sociedade contemporânea pode ser considerada a da era do enfraquecimento dos engajamentos coletivos. Em prol das condutas livremente escolhidas e assumidas pelos indivíduos, erodem-se as grandes narrativas, os discursos tradicionais. As ideologias políticas coletivas já não inflam multidões. Com uma visão talvez um pouco pessimista, Lipovetsky (2004) afirma que, em vez da disciplina, do laicismo e da vanguarda, prevalecem, atualmente, o indivíduo, o consumo e o hedonismo.

Em uma sociedade capitalista e pós-industrial, essa nova forma de autoconstrução - da individualização personalista -, com tamanha gama de ofertas a escolher para assim compor a existência individual, leva à radicalização de outro fenômeno: o consumo, que se tornou o principal vetor social de construção da individualidade (BAUMAN, 2001; LIPOVETSKY, 2004).

Se o consumo é o meio de construção do self, a identidade torna-se passageira, pois os produtos são temporais. No contexto do processo capitalista, os produtos alteram-se com as propagandas e, com eles, surge a necessidade de novos consumos e, consequentemente, a construção de novas identidades. A posse de determinados objetos de consumo passa a ser condição de conformação de 
identidade, a ser assumida ou não. Sem a obrigatoriedade da conduta condizente com a comunidade, o indivíduo torna-se livre da tradição, mas agora ele se encontra preso às amarras da lógica capitalista contemporânea. Sua liberdade é novamente limitada, pois suas opções de construção de identidades individuais dependem de recursos para o acesso ao consumo. É nesse sentido que os recursos facilitam ou dificultam a sobrevivência no mundo contemporâneo (BAUMAN, 2001).

Numa sociedade de consumo, compartilhar a dependência de consumidor - a dependência universal das compras - é a condição 'sine qua non' de toda liberdade; acima da liberdade de ser diferente, de ter identidade. (BAUMAN, 1998, p. 89).

Segundo a teoria de Bauman (1998), a centralidade do consumo opera objetivação e instrumentalização das relações sociais, ou seja, o processo de consumo afeta todas as relações, que passam a ser reduzidas às relações de consumo. Amizade, namoro, casamento, família são afetados pela lógica do consumo como o ideal do agir na sociedade contemporânea. Tornam-se também objetos de consumo - são úteis enquanto satisfazem e dispensáveis quando não mais possuem utilidade. As relações sociais na sociedade contemporânea constroem-se pela lógica do consumo, tornam-se voláteis e fluidas, e fragilizam as redes que sustentavam a coesão social estabelecida nos moldes da primeira modernidade.

O mundo construído de objetos duráveis foi substituído pelo de produtos disponíveis projetados para imediata obsolescência. Num mundo como esse, as identidades podem ser adotadas e 
descartadas como uma troca de roupa. 0 horror da nova situação é que todo diligente trabalho de construção pode mostrar-se inútil; e o fascínio da nova situação, por outro lado, se acha no fato de não estar comprometida por experiências passadas, de nunca ser irrevogavelmente anulada, sempre 'mantendo as opções abertas'. (BAUMAN, 1998, p. 112-113).

Em seu livro Modernidade líquida, Bauman (2001) afirmou que a sociedade saiu de um capitalismo pesado para um sistema capitalista fluido e leve. Tal capitalismo ativa, precisamente, o motor do consumo. No atual estágio do capitalismo, a relação mercadoria-consumo vem sendo transformada, pois, ao contrário do capitalismo pesado, em que a consigna era a acumulação de bens, na sociedade atual tem-se como mote a substituição do objeto consumido em uma temporalidade muito rápida. Esse fato é induzido pela intensidade das inovações tecnológicas. Diz o mesmo autor que, enquanto no capitalismo pesado o modo de produzir esteve fortemente ancorado na concepção fordista de racionalidade hierárquica e tecnocrática, a atual configuração da sociedade está ligada às velocidades das mudanças situacionais, que aportam flexibilização e conduzem a variadas formas de produção. De fato, a inovação é intrínseca a esse modo de produção e consumo, que é, também, incentivado por um marketing massivo e sedutor. Toda essa nova dinâmica atinge em cheio as relações de trabalho, tornando-as permanentemente instáveis.

Não obstante, independente da modalidade do capitalismo, ambas as suas formas aprisionam o consumidor pelo desejo e geram o vazio na impossibilidade de preencher e saciar sua vontade. Em suma, o excesso e a falta tangenciam o capitalismo leve e pesado (BAUMAN, 2001). 
Como se observa, para Bauman (2001), o consumo torna-se, no atual momento, a base principal pela qual o indivíduo constrói sua identidade. É por meio da incorporação simbólica absorvida com o consumo que se criam diferentes formas de identidade e sentimentos. Tem-se hoje, portanto, um vínculo entre a busca da felicidade e o consumo de mercadorias. Dessa forma, a busca frenética pela felicidade imposta pelas campanhas publicitárias impulsiona o descarte dos objetos, assim que novos são lançados. 0 consumo transforma a identidade e a felicidade em objetos a serem adquiridos.

A angústia da liberdade de escolha cria no consumidor a sensação de estar sempre a reinventar-se e a tecer sua própria história. No plano do inconsciente social, um objeto é ostentado como forma de integrar o indivíduo, que busca sair do anonimato e da impessoalidade para aderir à esfera da aceitação de um grupo no qual deseja inserir-se, ou seja, a busca do reconhecimento do outro (LIPOVETSKY, 2005a).

A dissolução do sujeito pelas regras da lógica do consumo cria uma nova identidade do indivíduo, que se identifica com mercado, como o modelo de individualização e personalização. No entanto, e contraditoriamente, os limites desse modelo são logo percebidos pelo indivíduo, pois os sentimentos construídos pelo consumo desses produtos fluidos destroem a autonomia desse mesmo indivíduo. A propósito, ao referirmos o consumo, não estamos a falar aqui somente das chamadas mercadorias-objeto, mas também de atividades de trabalho, de lazer etc.

Estamos destinados a consumir cada vez mais objetos, informação, esportes, viagens, formação, 
relações, músicas e cuidados médicos. Isto é a sociedade pós-moderna: não além do consumismo, mas sim, na sua apoteose, na sua extensão até a esfera particular [...]" (LIPOVETSKY, 2005a, p. 19).

Para Lipovetsky (2005a), o atual processo de individualização, a que ele denominou de narcisista, carrega uma nova característica intrínseca, que é a personalização. Nesse sentido, tudo é feito sob medida para o indivíduo: combinações de roupas, métodos de ensino, de atendimento, de tratamento médico, terapia psicanalítica etc. Tudo é personalizado e oferece a ideia de ser feito sob medida.

Na ordem psicoterapêutica, surgem novas técnicas que "[...] dão mais audácia ainda à personalização psicanalítica" (LYPOVETSKY, 2005a, p. 5), como as análises transacionais, grito primal e bioenergia, que permitem a liberação direta do sentimento, das emoções, da energia corporal. É a exploração mental/psíquica do corpo em ruptura com o diagnóstico puramente clínico. 0 corpo é bio-psíquico-social. "0 doente não deve mais aceitar seu estado passivamente, pois é o responsável pela sua saúde e pelos seus sistemas de defesa graças aos potenciais da autonomia psíquica" (LYPOVETSKY, 2005a, p. 5).

Em paralelo, os esportes e as atividades ao ar livre vêm ganhando cada vez mais espaço, sobretudo os esportes individuais e sob encomenda, que podem ajudar a psicologizar o corpo e desenvolver uma consciência sobre si mesmo: yoga, pilates, alongamento, corridas, ginástica laboral, natação, caminhada e bicicleta.

A cultura pós-moderna é a cultura do feeling e da emancipação individual estendida a todas as 
categorias de idade e de sexo. A educação, antes autoritária, tornou-se altamente permissiva, atenta aos desejos das crianças e dos adolescentes enquanto, por toda a parte, a onda hedonista elimina a culpa do tempo livre e encoraja a nossa entrega a ele sem entrave e o aumento da quantidade de lazer (LYPOVETSKY, 2005a, p. 5).

Segundo Lipovetsky (2005a), a sociedade atual passa a privilegiar a diversidade no oferecimento de serviços diferenciados nas diversas áreas da vida social, das relações sociais e das estruturas familiares, como na moda, no turismo, nos estudos, nos tratamentos de saúde e em outros mais. Nesse sentido, não se fala mais de homogeneização, mas na personalização das ofertas, tendo como objeto o indivíduo.

Da mesma forma que os indivíduos são plurais e distintos, tudo tem de parecer individualizado e distinto. 0 processo sistemático de personificação tem por finalidade "[...] multiplicar e diversificar a oferta, em oferecer mais para que você possa escolher melhor, em substituir a indução uniforme pela livre escolha, a homogeneidade pela pluralidade, a austeridade pela satisfação dos desejos" (LYPOVETSKY, 2005a, p. 3). Sua identidade não está mais definida pelo país de origem, pela concordância entre o sexo e sua designação social de gênero, pela família, idade, classe social e trabalho. Ela pode ser plural e modificar-se a todo o momento, segundo as escolhas feitas individualmente. Não é mais fixa nem deve acompanhar o indivíduo por toda sua vida. "[...] surgem por assim dizer módulos pré-fabricados de possibilidades combinatórias de natureza biográfica. Na transição da biografia padrão para a 22 biografia eletiva" (BECK, 2011, p. 199). 
Em suma, o individualismo da sociedade contemporânea diferencia-se do instituído pela sociedade moderna por não estar mais submisso às imposições e ordenamentos dos organismos ou instituições sociais. A valorização da noção de igualdade cedeu lugar à diferenciação, à liberdade de construção da identidade e à sobreposição do individual sobre o coletivo. Paradoxalmente, porém, a sociedade contemporânea tem criado novas formas de engessamento e padronização do indivíduo baseado no consumo. Tais transformações impactam as relações entre a sociedade e o Estado, bem como as instituições políticas modernas, impactos esses que serão objeto da explanação a seguir.

\section{TRANSFORMACŌEES SOCIOPOLITICAS}

Posto o panorama de individualização e consumo, cabe agora analisar a crise da institucionalidade do Estado em decorrência dos impactos das transformações da própria sociedade contemporânea. Parte-se do pressuposto de que há uma tripla crise: 1) crise da soberania do Estado-Nação, em virtude da globalização; 2) crise da governabilidade, em consequência das dificuldades do Estado na resposta às demandas sociais; 3) crise institucional do Estado, como resultado da falta de identificação da sociedade com as instituições governamentais e a própria política representativa.

A análise que segue está dividida em duas partes: a crise do Estado-Nação; e as transformações na relação entre a sociedade e as instituições políticas, abarcando a segunda e a terceira crises do Estado-Nação. 
Antes de ingressar nos motivos e nas consequências das crises e transformações do Estado na sociedade contemporânea, é necessário resgatar como a política e a institucionalidade do Estado manifestaram-se no período que denominamos de primeira modernidade (que vai do início da Revolução Industrial até o declínio da ordem social socialista).

A ideia de política moderna tem como característica primordial o seu desenvolvimento em um espaço delimitado territorialmente, vale dizer, nos limites do próprio Estado-Nação.

A história da formação do Estado-Nação percorreu um longo período do processo histórico, carregado, muitas vezes, de violência. Passou pelo estabelecimento e consolidação de uma autoridade central (o rei), em que os feudos a ela submeteram-se, com a participação, embora algumas vezes contraditória, de uma organização supranacional, a da igreja. 0 resultado desse arranjo institucional, decorrente da imposição da autoridade central do monarca, vincula-se, intimamente, à própria constituição do capitalismo. 0 poder central definiu o seu território (a Nação), que, por sua vez, deu identidade política aos habitantes desse território (DALLARI, 2001).

Segundo Dallari (2001), os conceitos inerentes ao Estado-Nação são: o território, o povo e a soberania. Território é a extensão necessária para o Estado localizar-se no espaço terrestre, marítimo e aéreo. Povo é o conjunto de indivíduos que integra o Estado por meio da vinculação jurídica e, assim, adquire a condição de cidadãos. É da intersecção dos conceitos de povo e território que surge a ideia de nação. Nação é a comunidade de base histórico-político-cultural que integra todos os indivíduos que 
nascem em certo ambiente cultural, com tradições e línguas comuns. Por fim, soberania está relacionada com a ideia de autoridade suprema. É o direito exclusivo de uma autoridade sobre um grupo de indivíduos. A soberania se manifesta, principalmente, pela constituição de um sistema de normas jurídicas (DALLARI, 2001; BOBBIO, 1999).

[...] tendo em conta a possibilidade e a conveniência de se acentuar o componente jurídico do Estado, sem perder de vista a presença necessária dos fatores não-jurídicos, parece-nos que se poderá conceituar o Estado como a ordem jurídica soberana que tem por fim o bem comum de um povo situado em determinado território. Nesse conceito se acham presentes todos os elementos que compõem o Estado, e só esses elementos. A noção de poder está implícita na de soberania, que, no entanto, é referida como característica da própria ordem jurídica. A politicidade do Estado é afirmada na referência expressa ao bem comum, com a vinculação deste a um certo povo e, finalmente, territorialidade, limitadora da ação jurídica e política do Estado, está presente na menção a determinado território. (DALLARI, 2001, p. 45).

A respeito da relação Estado, direito, soberania e poder, Dallari (2001) afirma que o Estado deve procurar o máximo de juridicidade e que em seu caráter de ordem jurídica estão sintetizados os elementos componentes do Estado. Contudo, ele explica que isso não é nada fácil, pois,

[...] enquanto sociedade política, voltada para fins políticos, o Estado participa da natureza política, que convive com a jurídica, influenciando-a e sendo por ela influenciada, devendo, portanto, exercer um poder político. Este é o aspecto mais difícil 
e mais fascinante do estudo do Estado, pois introduz o estudioso numa problemática extremamente rica, dinâmica e polêmica, onde se faz presente a busca dos valores fundamentais do indivíduo, da sociedade e do Estado, a par da procura da organização mais eficaz para a promoção desses valores. (DALLARI, 2001, p. 48).

0 autor aponta, ainda, um quarto elemento relativo à concepção do Estado, qual seja, suas funções e finalidades. Tal concepção diz respeito ao conteúdo relativo a toda atividade estatal, que determina a estrutura fundamental do Estado (burocracia e máquina pública) que, em síntese, organiza suas atividades por meio de regras racionais, gerais e abstratas, travestidas na lei emanada do próprio Estado.

Os processos mais significativos na constituição do Estado-Nação foram: fronteiras territoriais, sistema uniforme de leis, mecanismos de elaboração e imposição das leis, centralização do poder administrativo, estabelecimento de impostos e gestão fiscal, criação de uma força armada nacional - exército e constituição de uma diplomacia para regular as relações entre os Estados. É formado por um aparato de instituições que exercem os poderes político, administrativo e normativo. A conformidade da sociedade moderna exigiu, assim, um poder centralizado que concentrasse os instrumentos capazes de administrar os desafios e as exigências de uma economia capitalista. 0 Estado, por assim dizer, é uma manifestação moderna decorrente do processo de racionalização (WEBER,1998; BOBBIO, 1987).

Podemos vislumbrar essas características a partir de teorias da soberania estatal em pensadores contratualistas, como Hobbes (1999), Locke (2006) e Rousseau (1999). Hobbes (1999) foi um dos primeiros teóricos a 
tratar da noção central de soberania de um Estado e das condições para o exercício legítimo sobre um território e uma população. Posteriormente, a ideia de soberania do Estado transformou-se em soberania popular com Locke (2006) e Rousseau (1999), dos quais emerge a noção de que a fonte e a origem do poder político devem ser consentidas pelos cidadãos. E assim, gradativamente, expande-se a noção da democracia moderna, em que a origem da soberania do poder Estatal dá-se pela vontade geral.

Apesar da relevância de tais autores para o pensamento moderno, aqui nos deteremos em dois outros estudiosos que permearam as teorias sociológicas e políticas no século XX e que foram, de alguma forma, influenciados pelos anteriores, são eles: Max Weber e Antônio Gramsci.

Weber (1998) identifica como característica do Estado moderno a dominação racional, baseada na crença da legalidade das ordenações, fundada em regras racionalmente criadas - as leis. O Estado moderno seria, portanto, uma instituição racional que agiria por meio de uma administração estabelecida constituída de uma burocracia e de uma concepção jurídica, nas quais essa administração deve ser pautada. Segundo esse raciocínio, o Estado moderno abrange atributos da força física, da noção de território e da burocracia.

No que concerne ao exercício do monopólio da coação física legitimada, o Estado moderno é "[...] uma relação de domínio de homens sobre homens, baseada no instrumento de força legítima (quer dizer, considerada legítima). 0 Estado só pode existir, portanto, sob a condição de que os dominados submetam-se à autoridade continuamente reivindicada pelos que dominam" (WEBER, 1996, p. 56 apud NOGUEIRA, 2013, p. 337). 
Com relação ao território, é ele que estabelece os limites do exercício da coação física. A atividade política é definida pelo fato de desenrolar-se no território delimitado. É, portanto, necessário que as fronteiras sejam fixadas e que se delimite um agrupamento, criando-se uma separação entre o interior e o exterior. Os que estão no interior, os cidadãos, adotam um comportamento orientado segundo o território e a comunidade correspondente, e têm suas atividades e os limites de sua liberdade condicionados pela autoridade encarregada da ordem, o Estado (WEBER, 1998).

Constitui ainda característica do Estado moderno a burocracia, os funcionários do Estado que pautam suas atividades segundo regras racionais, gerais e abstratas: a lei emanada do próprio Estado, sendo, portanto, uma atividade impessoal e vinculada. Isso quer dizer que a necessidade de racionalização faria com que o Estado se legitimasse e crescesse com uma burocracia capaz de incrementar o poder político mediante rotinas técnicas, administrativas e legais. A burocracia seria a própria capacidade de organização da máquina administrativa do Estado moderno (WEBER, 1998).

Já Gramsci (1968), por sua vez, foi um pensador que rompeu com a tradição jusnaturalista ao pressupor a existência de formas de associação que antecedem o Estado e que correspondem à sociedade civil. Ele não abandona a dicotomia estrutura/superestrutura pela sociedade civil/Estado, mas também não desenvolve sua teoria com base no determinismo econômico de Marx, envolvido na primeira dicotomia. De acordo com Carnoy (1988), a distinção entre Gramsci e Marx é que, na concepção marxista, a sociedade civil é estrutura, ou seja, ela representa as 
relações de produção. Na concepção gramsciana, ela é a superestrutura, isto é, corresponde às relações de produção. No que concerne à concepção gramsciana, ela corresponde aos fatores ativo e positivo no desenvolvimento histórico, ou seja, é a superestrutura. Nesse sentido, para Gramsci (1968), a sociedade civil é o complexo das relações ideológicas, culturais e intelectual.

Segundo Gramsci (1968), a superestrutura conta com dois níveis, a sociedade política e a civil, sendo a primeira o conjunto de mecanismos por meio dos quais a classe dominante dispõe o monopólio da violência (burocracias e Forças Armadas), e a segunda, o conjunto de organizações públicas e privadas responsáveis por elaborar e difundir as ideologias. É nesse sentido que esse pensador amplia o conceito de Estado, ao afirmar que "[...] na noção geral de Estado entram elementos que também são comuns à noção de sociedade civil (neste sentido, poder-se-ia dizer que Estado = sociedade política + sociedade civil, isto é, hegemonia revestida de coerção)" (GRAMSCI, 1968, p. 149).

0 Estado é assim definido como "[...] todo o conjunto de atividades teóricas e práticas com as quais a classe dirigente justifica e mantém não somente a sua dominação, mas também consegue obter o consenso ativo dos governados" (GRAMSCI, 1976, p. 87).

Posto esse rápido panorama da construção teórica do Estado Moderno, cabe agora analisar as transformações pelas quais ele vem passando na sociedade contemporânea.

Como já citado na primeira parte deste capítulo, a política, na primeira modernidade, estava centrada no Estado, ou seja, dentro dos limites do Estado-Nação é que ela 
se manifestava. Essa é uma das características que mais sofreu alteração com as transformações da sociedade contemporânea, visto que essa ideia de fronteira trazia consigo o processo conhecido por desterritorialização.

A manifestação mais eloquente da desterritorialização é o fenômeno da globalização, que Giddens (1991, p. 69) define como sendo "[...] a intensificação das relações sociais em escala mundial, que ligam localidades distantes de tal maneira que os acontecimentos locais são modelados por eventos ocorrendo a muitas milhas de distância e vice-versa”.

Com o fenômeno da globalização na segunda metade do século XX, o Estado-Nação passou a sofrer a competição de instituições supranacionais de poder. Na globalização, segundo Giddens (1997), os laços estendem-se muito além das fronteiras tradicionais das comunidades e das nações, levando em si um novo sentido de organização social e política. Dessa forma, as relações sociais ultrapassam os contextos locais de interação e são reorganizadas em outra magnitude de tempo e espaço. A história, a cultura, as relações, as vivências individuais e coletivas são modificadas cotidianamente. Tudo é transformado pela velocidade eletrônica, imprimindo novos ritmos à sociedade em rede (CASTELLS, 1999a).

A vida das nações, empresas, instituições e partidos torna-se, de modo geral, organizada segundo padrões universais de eficácia, lucro e produtividade. Essa razão instrumental começa a ordenar tempo e espaço, o modo de consumo, de pensar e agir. Consequentemente, as identidades culturais pré-modernas acabam enfraquecendo. Simulacros, virtualidades e imagens passam a desempenhar papel importante na vida social, à medida que aceleram a 
racionalização das organizações e as atividades baseadas na técnica, na eletrônica e na informática (IANNI, 2003).

Dessa forma, assistimos ao enfraquecimento das fronteiras, ao surgimento de capital volátil e até mesmo ao afrouxamento do poder soberano do Estado-Nação, que, assim, tem vivido uma crise de legitimidade tanto de suas instituições como de seus representantes, pois, confrontado com fluxos globais de capitais, de produção, de comércio, de informação e de gestão, foi perdendo parte de seu poder. 0 Estado tem passado pelo desafio de aprender a navegar em fluxos globais, bem como a ressignificar seu poder de soberano em termos de governo ante a sociedade, modelo que esteve na base de sua formação.

[...] os quadros mentais de referência, fortemente enraizados na hipótese da sociedade nacional, do Estado-Nação, adquirem outras possibilidades de expressão. Rompem-se os significados dos conceitos, categorias, leis e interpretações codificados nas noções de sociedade civil, Estado Nacional, povo, cidadão, classe social, grupos étnicos, movimento social, partido político, corrente de opinião pública, diversidade, desigualdades, antagonismos. (IANNI, 1997, p. 105).

A luta política na modernidade tinha como palco e objetivo a conquista e a manutenção do poder estatal, visando o bem comum e um interesse geral da nação. Já na sociedade contemporânea, com a intensificação do processo de individualização, o jogo político ocorre na arena da sociedade civil. Aqui se tem, como proposta, a conquista de finalidades grupais ou segmentares, pois seus fins visam a interesses micros e individuais.

Segundo Rouanet (1992, p. 237), 
[...] assim como não há mais atores políticos universais - grandes partidos agregando um leque amplo de interesses e posições -, não há mais um 'poder' central localizado no Estado, mas um poder difuso, estendendo sua rede capilar por toda a sociedade civil - as 'disciplinas' de Foucault. Políticas segmentares, exercidas por grupos particulares, política micrológica, destinada a combater o poder instalado nos interstícios mais imperceptíveis da vida cotidiana, estamos longe da política moderna, em que o jogo político se dava através de partidos, segundo os mecanismos da democracia representativa.

Os cidadãos, como sujeitos coletivos, pulverizaram-se em suas características individuais, restringindo-se às suas particularidades de mulher, negro, judeu, homossexual etc. Consequentemente, a política universalista/genérica passa a não ser mais efetiva ou mesmo legitimada por seus públicos-alvo. 0 cidadão exige, assim, políticas específicas, inscritas nos campos setoriais da diversidade existente na sociedade.

Pode-se aferir que, em meio a essas grandes transformações, a política institucional e o campo das administrações públicas também sofrem impactos. Apesar de elas ainda estarem ancoradas na lógica do território nacional e da soberania, constituídas na modernidade, é nítido que se torna cada vez mais árduo ao Estado responder à sociedade com base nessa lógica, o que demonstra um descompasso das instituições públicas com as transformações sociais. "El mercado y el poder económico subyacente se han globalizado, mientras las instituiciones politicas, y el poder que de ellas emana, siguen en buena parte anclados 32 al território" (SUBIRATS, 2012, p. 2). 
Se o projeto moderno aspirava a uma sociedade planejada e administrada de forma científica para a definição de uma política pública, é porque se acreditava que o conhecimento produzido pela ciência seria garantia de sucesso. Hoje, sabe-se que esse projeto moderno não atingiu seu objetivo e têm-se a certeza de que a ciência não é um saber positivo e neutro. Sabe-se também que para elaborar uma política pública, como um programa de saúde, os atores responsáveis por sua elaboração e execução devem contemplar um conjunto de aspectos alheios à ciência, mas que interferem no alcance de suas metas. São aspectos ideológicos, políticos, culturais, institucionais e éticos. Ademais, devem-se contemplar todos os atores envolvidos na política e o próprio público-alvo. 0 Estado já não pode mais elaborar e executar sozinho a política pública, nem elaborá-la de forma homogênea, sem considerar as distinções existentes na sociedade.

Para Subirats (2012), a lógica hierárquica formal não serve mais para fundamentar o processo de decisão pública, que cada vez mais encontra-se baseado na lógica da interdependência e relacional.

Se ha ido poniendo de relieve que el Estado no es ya la representación democrática única e indiscutida de un conjunto de indivíduos, sino un simples actor a más en el escenario social. Un actor a más, y muchas veces, no el más fuerte, en la dinámica del mercado global. Un actor que resulta cada vez más condicionado y limitado en su capacidad de accíon por la creciente colusión de sus políticas con los intereses privados. (ibidem, p. 3).

Argumenta-se, pois, que a sociedade industrial moderna vem-se desestabilizando em sua própria estrutura, 
tornando-se cada vez mais complexa e abrangendo as tendências particulares do mundo pós-industrial, quais sejam: a desvalorização da política e a crise do Estado como instância de coordenação e planejamento; a fragmentação e a diversificação dos interesses; e o crescimento do individualismo (NOGUEIRA, 2001).

Em relação à política, essa crise implica o esvaziamento das instituições democráticas e o comportamento autoritário e tecnocrata dos poderes executivos. É visível hoje a inabilidade dos partidos políticos e do próprio Estado em lidar com a dinâmica social, com situações complexas e diferenciadas que se modificam rapidamente e exigem não só maior rapidez nas respostas, como também a participação mais efetiva dos atores sociais, sem ser pelas vias institucionais existentes (por exemplo, os conselhos, que se tornam instâncias cooptadas pela burocracia administrativa).

Basicamente, podemos citar dois fenômenos que dificultam a resposta do Estado às demandas sociais, bem como a falta de identificação da sociedade com as instituições governamentais e a própria política representativa: o pluralismo social, que traz em sua essência o direito de ser diferente (consequência do fenômeno do individualismo), e a emergência de um novo tempo/espaço tecnológico.

Com relação ao primeiro, o pluralismo basicamente afeta a política em dois quesitos: a necessidade por políticas específicas e não mais homogêneas, e a demanda por mais direitos e reconhecimentos individuais. Como pontua Carvalho (2009), nessa tendência ideológica e nesse momento histórico, o direito ao consumo desponta como o pilar da sociedade contemporânea. 0 novo cidadão desponta como consumidor de direitos, de reconhecimento, de mercadorias, de cultura, de identidades, de saúde. 
Dessa maneira, podemos aproximar o discurso de Carvalho (2009) ao de Bauman (1999a) e Lipovetsky (2005a; 2005b) à multiplicidade dos direitos individuais. A sociedade contemporânea é caracterizada pela tendência a aumentar a oportunidade das escolhas individuais de tal maneira que os cidadãos pulverizam-se em suas características individuais e demandam, cada vez, mais direitos específicos relacionados à sua individualidade.

Dessa forma, na sociedade contemporânea, devido ao pluralismo social existente, há uma imensa luta por novos direitos e novos reconhecimentos identitários. Há o aumento e a diversificação de demandas individuais e minoritárias - exigências que se tornam cada vez mais difíceis de serem atendidas. 0 Estado-Nação, que desde seu nascimento esteve voltado a administrar o coletivo e a produzir políticas homogêneas, vê-se na encruzilhada de conseguir administrar direitos e demandas individuais.

As mudanças ocorridas no padrão da demanda são um indício forte de que a dinâmica dos processos políticos tornou-se mais rica e complexa. São demandas pelo direito ao casamento homoafetivo, por tratamentos de saúde específicos, pela reprodução assistida, pela escolha de determinado serviço de saúde ou terapêutica - um hospital, certo tratamento medicamentoso, por exemplo -, pelo transporte, pela educação, por terapia, por praticar esporte etc. São demandas individualizadas ou de grupos específicos. Não são mais estritamente de uma classe.

Os interesses, as exigências e as reivindicações fragmentaram-se, sobrecarregando os processos e procedimentos da representação e da decisão política. 0 jogo político é hoje segmentar, exercido sob formas particulares e muito distinto do da política moderna, em que os jogos 
políticos davam-se por meio dos partidos e segundo os mecanismos da democracia representativa.

Os partidos políticos não representam mais as inúmeras identidades sociais, pois estas, na sociedade contemporânea, são individuais, são micrológicas. Não são mais as classes, mas sim os elementos que constituem suas particularidades: a de ser mulher, negro, homossexual, judeu e outras. A sociedade civil fragmentou-se em grupos identitários e, portanto, suas demandas são individualizadas.

0 movimento de individualização que se alastra no Ocidente desde a segunda metade do século XX é um elemento paradoxal, emergido dentro da própria sociedade capitalista industrial e que vem gestando uma nova forma de sociabilidade e apresentando um desafio para as próprias instituições políticas que não conseguem compreendê-lo.

A cultura pós-moderna representa o pólo 'supernatural' de uma sociedade que está saindo de um tipo de organização uniforme, administrativa e que, ao fazê-lo, enfraquece os últimos valores modernos, reergue o passado e a tradição, torna a valorizar o lugar e a vida simples, dilui a preeminência da centralização, dissemina os critérios do verdadeiro e da arte, legitima a afirmação da identidade pessoal de acordo com os valores de uma sociedade personalizada na qual o importante é ser a própria pessoa e onde, por conseguinte, qualquer coisa tem direito de cidadania e de reconhecimento social, onde nada mais deve ser exigido imperiosa e duravelmente, onde todas as opções, todos os níveis podem conviver sem contradição nem relegação (LYPOVETSKY, 2005a, p. 20).

0 questionamento da tradição, o hiperindividualismo e a instabilidade das normas de socialização colocam 
em risco a coesão social contemporânea e o desengajamento político? Não. É curioso notar que o individualismo não elimina a participação coletiva, somente altera a forma pela qual ela ocorre. 0 engajamento coletivo contemporâneo dá-se pela lógica da individualização.

Muitas vezes, os interesses individuais prevalecem sobre os sociais, a autonomia individual sobre a ortodoxia doutrinal, a participação livre sobre a coletividade, a ação direta sobre a representatividade. 0 esvaziamento dos grandes movimentos sociais e o enfraquecimento da credibilidade dos partidos políticos como instituições detentoras de grandes perspectivas históricas são sintomas das características dos novos paradigmas contemporâneos.

Lipovetsky (2005a) considera que o advento da sociedade hiperindividualista não põe fim às lutas sociais, pois, em meio ao individualismo, surgem variadas formas de engajamento em ações coletivas com as quais os indivíduos podem envolver-se livremente, sem se submeterem a qualquer instância superior. A existência de autonomia privada reencontra-se nas ações coletivas, independentemente das organizações políticas e sindicais. Mobilizações, muitas vezes e aparentemente despolitizadas, desideologizadas e dessindicalizadas, aparecem por toda parte, sustentadas pelas reivindicações individualistas de melhoria das condições de trabalho, transporte, moradia, poder de consumo etc.

Para Lipovetsky (2004), o predomínio do ego avança sobre o terreno das ações coletivas em proveito dos próprios indivíduos. Tais avanços ocorrem nas mais diversas dimensões (política, econômica, cultural etc.), afastando-as das utopias modernas e aproximando-as dos interesses 
particulares. "[...] embora o sacerdócio do dever e os tabus vitorianos tenham caducado, nascem novas regulações, reconstituem-se proibições, restauram-se valores" (LIPOVETSKY, 2004, p. 38). A sociedade civil imprime uma nova ordem, ainda difícil de compreender, se a olharmos com base nos paradigmas modernos, ou sólidos, como denomina Bauman (2001).

Na análise de Lipovestky (2005b), em A sociedade pós-moralista, é preciso entender o que está no centro das motivações individuais quanto a ações e ajustamentos específicos em prol de soluções práticas para problemas como a miséria, a fome, as epidemias e o meio ambiente, dentre outros, pois são questões que refletem preocupações de fundo com as grandes falhas do projeto moderno relegadas para a sociedade atual. Não que tais engajamentos não sejam verdadeiros e pertinentes, porém, para o autor, essas iniciativas, que portam um inconsciente particular de alívio e de conforto social, podem expressar exatamente a realidade e ênfase em projetos individuais.

Na sociedade contemporânea, não há nada que provoque, no indivíduo, o sentimento de obrigatoriedade. Nem a religião ou mesmo as instituições sociais têm a competência de motivar, no indivíduo, uma suposta responsabilidade sua para com o coletivo. É essa falta de obrigatoriedade que, segundo Lipovetsky (2005b), define o hiperindivíduo na sociedade contemporânea.

Cabe, agora, analisar o segundo fenômeno que dificulta ao Estado dar respostas às demandas sociais, bem como a falta de identificação da sociedade com as instituições governamentais e a própria política representativa: a emergência de um novo tempo/espaço tecnológico. 
0 atual momento histórico, segundo Castells (1999a), é marcado pela Revolução Informacional e Tecnológica, que tem como característica as grandes redes comunicacionais. De acordo com o autor, vivemos em uma era em que a comunicação superou as barreiras impostas pelas distâncias físicas, em que a internet e a sociedade em rede têm permitido a troca de informações de forma instantânea. Formam-se redes independentes das instâncias do mercado ou do governo, o que permite a emergência do que Castells (1999a, p. 23) denominou de "[...] comunicação de massa autocomandada". É comunicação de massa por estar disponível em toda internet e autocomandada porque pode ser iniciada por qualquer indivíduo com acesso à rede.

Castells (1999a, p. 24) afirma que,

[...] uma vez que a política é largamente dependente do espaço público da comunicação em sociedade, o processo político é transformado em função das condições da cultura da virtualidade real. As opiniões políticas e o comportamento político são formados no espaço da comunicação.

A análise de Castells (1999a) permite afirmar que a atual participação da sociedade civil na política atrelou-se às novas tecnologias de comunicação e informação. Sob essa ótica, a participação dá-se pela interatividade no ciberespaço, que garante a transcendência virtual dos aspectos territoriais e culturais locais. Nesse sentido, é necessário destacar o impacto político do aparecimento da internet, que, ao descentralizar os sistemas de comunicação, fez do indivíduo não somente um consumidor, mas também um produtor de informação e controlador do seu meio de comunicação. 
A internet se converteu em um novo espaço, não mais territorial, de expressão política. Por meio das comunidades virtuais, blogs etc., novas formas de participação e de fazer política emergiram sem que ocorressem pelos meios/espaços institucionais tradicionalmente instituídos pelo Estado. Tal fenômeno faz com que a sociedade civil não se identifique mais com esses meios/espaços tradicionais de participação da vida pública, e a atual política representativa tem sua operacionalidade reduzida. Há, portanto, um descompasso entre as instituições políticas democráticas e a própria forma de fazer política na sociedade contemporânea. É precisamente por isso que a participação política contemporânea não se restringe mais no direito ao voto ou em outros direitos formais garantidos por via externa. Esse tipo de participação dava-se na cidadania moderna, tradicional, quando o Estado era o mediador de seu exercício. No atual contexto, as formas de participação dão-se livres de determinadas amarras do Estado mediador, tornando o exercício da cidadania mais ampliado e direto.

Ademais, a tecnologia da informação trouxe o imediatismo, a velocidade, encurtou o tempo e o espaço. A sociedade é a do hoje, do agora. Já o tempo da política e da administração pública é outro, mais lento e burocrático. A burocracia leva a um engessamento da máquina pública e a uma demora em responder à demanda social, resultando em um descrédito por parte da sociedade.

Conclui-se, portanto, que as instituições e práticas típicas do Estado-Nação são correspondentemente debilitadas. Observa-se que a democracia representativa e as formas institucionais de representação cedem lugar à 
participação ativa e direta na internet e aos grupos sociais minoritários e diversos. Também tomam formas mais pluralizadas as identidades coletivas de classe, assim como os aspectos culturais e a própria identidade nacional cedeu lugar a culturas minoritárias. A característica da sociedade atual está mais centrada na pluralidade e diversidade dos grupos multiculturais, fazendo sobressair a diferença e não mais a identificação coletiva de classe, por exemplo. Isso faz com que a identidade torne-se, situacionalmente, fluida e cambiante a cada instante.

Como consequência desse processo tecnológico de produção de individualização, a relação entre o indivíduo e o Poder Público passa a sofrer mutações, o que deflagra novas conformações ao que tradicionalmente se entende como uma relação do Estado com seus cidadãos e, consequentemente, ao atendimento das suas necessidades. E é desse conceito que trataremos no próximo capítulo deste livro. 